\section{Sox9 expression in canine epithelial skin tumors}

\section{E. Fantinato, L. Milani, G. Sironi \\ Department of Veterinary Science and Public Health, School of Veterinary Medicine, Veterinary University Hospital, Pathology Unit, University of Milan, Lodi, Italy}

\begin{abstract}
Sox 9 is a master regulatory gene involved in developmental processes, stem cells maintenance and tumorigenesis. This gene is expressed in healthy skin but even in several skin neoplasms, where its expression patterns often resembles those of the developing hair follicle. In this study, samples from eleven different types of canine skin neoplasms (squamous papilloma, squamous cell carcinoma, infundibular keratinizing acanthoma, inferior tricholemmoma, isthmic tricholemmoma, trichoblastoma, trichoepithelioma, malignant trichoepithelioma, pilomatricoma, subungual keratoacanthoma, subungual squamous cell carcinoma) were immunohistochemically stained and evaluated for $\operatorname{Sox} 9$ with the aim to correlate tumor phenotype with molecular characteristics that may help to better define tumor development, contribute to its diagnosis and clinical management. Keratoacanthoma excluded, all the skin neoplasms examined showed a variable positivity to $\operatorname{Sox} 9$, especially in the basal layers, but with major intensity in neoplasms developing from the bulge region of the hair follicle, as trichoblastoma. According to our results, Sox9 could be employed as a stem cell marker to better assess the role of stem cells in canine epidermal and follicular tumors.
\end{abstract}

\section{Introduction}

The SRY sex determining region Y-box 9 (Sox9) is a transcription factor involved in high mobility group box transcription factor family, that plays a key role in directing tissue and cell morphogenesis, survival, and development. ${ }^{1}$ Sox 9 mutations were identified in 1994 as responsible for campomelic dysplasia, a rare skeletal dysplasia associated with $\mathrm{XY}$ sex reversal. ${ }^{2}$ So $x 9$ has emerged as a key regulator of various developmental processes; ${ }^{3}$ in the skin, in particular, Sox 9 is expressed in the sebaceous gland, sweat gland, outer root sheath of the hair follicles ${ }^{1,3}$ and in the hair stem cells located in the bulge ${ }^{3}$ The bulge represents a highly specialized hair follicle niche that preserves the proliferative potential of adult stem cell. ${ }^{4}$ The hair follicle, indeed, represents an important stem cell reservoir in the skin, both for epithelial stem cells $s^{1,3}$ and for mesenchimal stem cells. ${ }^{5}$ Besides to be essential for outer root sheath differentiation and the formation of hair stem cell compartment itself, ${ }^{6}$ Sox 9 is expressed in epithelial stem cells in adult hair follicle, that give rise to all epithelial cells of the hair follicle, the sebaceous gland, and the interfollicular epidermis. ${ }^{7}$ According to recent studies indeed, adult stem cells are involved in tissue homeostasis maintenance and in wound healing processes. ${ }^{4}$ In mouse, $\operatorname{Sox} 9$ absence in early stem cells can block hair follicle morphogenesis and epidermal wound repair. ${ }^{1,4}$

Sox9 is highly expressed in several skin diseases as psoriasis or acne, ${ }^{1}$ and generally in adnexal-related neoplasms, ${ }^{1,3,8}$ basal cell carcinoma ${ }^{3}$ squamous cell carcinoma ${ }^{1}$ and metastatic melanoma. ${ }^{9}$ The role of $\operatorname{Sox} 9$ in skin tumorigenesis, however, needs to be clarified yet. ${ }^{1}$ Among various specific human bulge markers that are similarly overexpressed in canine bulge cells, Sox 9 is one of the most represented. Canine bulge stem cells, indeed, strongly resemble distribution and biochemical features of the human ones. ${ }^{10}$

The aim of this study was to investigate the immunopositivity for $\operatorname{Sox} 9$ in different canine epidermal and hair follicle neoplasms; differences in $S o x 9$ expression would help to correlate tumor phenotype with molecular characteristics thus allowing to better define tumor development, contribute to its diagnosis and clinical management.

\section{Materials and Methods}

\section{Case selection}

Different types of canine epithelial tumors were retrieved from the files of the Department of Veterinary Pathology, Hygiene and Public Health of Milan. Samples of squamous papilloma $(n=5)$, squamous cell carcinoma $(n=6)$, infundibular keratinizing acanthoma $(n=4)$, inferior tricholemmoma $(\mathrm{n}=5)$, isthmic tricholemmoma $(\mathrm{n}=2)$, trichoblastoma $(\mathrm{n}=12)$, trichoepithelioma $(n=7)$, malignan trichoepithelioma $(n=3)$, pilomatricoma $(n=2)$, subungual keratoacanthoma $(n=1)$, subungual squamous cell carcinoma $(n=4)$ were selected. Normal skin tissue surrounding the tumor was also included in the study.

The diagnosis of each tumor was revised according to the criteria of the World Health Organization classification.
Correspondence: Dr. Eleonora Fantinato, Department of Veterinary Science and Public Health, School of Veterinary Medicine, Veterinary University Hospital, Pathology Unit, University of Milan, Via dell'Università 6, 26900 Lodi, Italy. Tel. +39.02.50331162 - Fax: +39.02.50331115. E-mail: eleonora.fantinato@unimi.it

Key words: Sox9; dog; epidermal tumors; hair follicle tumors; immunohistochemistry.

Contributions: EF, immunohistochemistry performing, manuscript writing contribution, figures preparation, microscopic analysis and data collection; LM, manuscript writing contribution, microscopic analysis and data collection; GS, project design, manuscript writing contribution, microscopic analysis and data collection.

Conflict of interest: the authors declare no conflict of interest.

Received for publication: 26 February 2015. Accepted for publication: 15 May 2015.

This work is licensed under a Creative Commons Attribution NonCommercial 3.0 License (CC BYNC 3.0).

(C) Copyright E. Fantinato, et al., 2015

Licensee PAGEPress, Italy

European Journal of Histochemistry 2015; 59:2514 doi:10.4081/ejh.2014.2514

\section{Immunohistochemical staining}

Four-micrometer thick sections from routinely formalin-fixed and paraffin-wax embedded samples were prepared on poly-L-lysinecoated glass slides for immunohistochemistry. The sections were deparaffinized in xylene and rehydrated through graded alcohols. Endogenous peroxidase was blocked using 3\% hydrogen peroxide in distilled water for $5 \mathrm{~min}$, then, antigen retrieval for formalin-fixed samples was accomplished by microwave irradiation in citrate buffer, $\mathrm{pH} 6.0$, for $10 \mathrm{~min}$. Normal goat serum for 30 min was employed to block sections. Sections were then incubated for $18 \mathrm{~h}$ at $4{ }^{\circ} \mathrm{C}$ with anti-Sox9 rabbit polyclonal antibody (HPA001758; Sigma-Aldrich, St. Louis, MO, USA) diluted 1:200. The antibody recognizes a Sox9 specific peptide of 117 amino acids with $96 \%$ identity with Canis familiaris. The sections were incubated for 30 min with 1:200 goat anti-rabbit biotin conjugate antibody (Vector Laboratories, Burlingame, CA, USA; BA 1000) and subsequently stained for 30 min with streptavidinbiotin peroxidase kit (Vectastain Elite ABC, Vector Laboratories, PK-6100). Positive staining was visualized with 3.3- diaminobenzidine-4 $\mathrm{HCl}$ (Vectastain, Vector Laboratories, SK-4100) and nuclei were counterstained with Mayer's hematoxylin. Sox9 reactivity of follicu- 
lar outer root sheath present in normal cutaneous tissue of tumor sample was used as internal positive control. Negative control sections were produced by omission of the primary antibody.

\section{Evaluation of immunohistochemical data}

The immunohistochemically stained tissue slides were examined using standard light microscopy. The staining results were independently scored by the authors as follows: Sox9 protein expression was assessed by categorizing immunoreaction of each tumor cell type into four groups according to the proportion of positive cells: 0 , no positive cells; 1 , from $1 \%$ to $25 \%$ positive cells; 2 , from $25 \%$ to $50 \%$; 3 , from $50 \%$ to $75 \%$; 4 , from $75 \%$ to $100 \%$. The intensity of labeling was graded as: W, weak positive staining; $\mathrm{M}$, moderate positive staining; I, intense positive staining, and scored as follows: $\mathrm{W}=1, \mathrm{M}=2, \mathrm{I}=3$. A global score was conferred adding together the positive cells percentage score and the intensity of immunolabeling score.

\section{Results}

Sox9 immunohistochemical results are reported in Table 1 . In every section a portion of healthy skin next to the neoplasms was always included, as Sox9 internal positive tissue control (Figure 1A). Immunohistochemical examination resulted always positive. In normal skin, Sox 9 positive reaction was restricted to the bulge region and outer root sheath of the hair follicles and to germinative cells of the sebaceous glands. Well differentiated sebocytes, sweat glands and epidermal cells were mostly negative. Only in a few cases Sox9 positive epithelial cells were present in basal and spinous layers of hyperplastic, reactive epidermis near and above the neoplastic tissue.

\section{Squamous papilloma}

In 4 of 5 squamous papillomas the number of Sox9 positive cells varied from 1-25\% (1 case) to $25-50 \%$ (1 case), or $50-75 \%$ (2 cases) showing moderate to intense immunolabeling, staining especially basal and suprabasal cells. Only in 1 case, the percentage of Sox 9 positive cells ranged from $1 \%$ to $25 \%$ and appeared weakly positive.

\section{Squamous cell carcinoma}

Sox9 was positive in all 6 squamous cell carcinomas (Figure 1B), with a variable number of positive cells, extending from 1-25\% (2 cases) to $25-50 \%$ ( 2 cases) or $50-75 \%$ (2 cases). The intensity of staining being intense in 1 case, moderate in 2 , weak in 3 . Immunolabeling involved especially basal cell layer and spinous cells, even if in 3 cases its distribution was very irregular.

\section{Infundibular keratinizing acanthoma}

Sox9 showed a variable positivity: in all 4 cases, ranging from a rare and weak staining ( 2 cases) to a diffuse and intense immunolabeling (1 case).

Table 1. Sox9 immunohistochemical results.

\begin{tabular}{|c|c|c|c|c|}
\hline Neoplasm & Case no. & Positive cells & Signal intensity & Global score \\
\hline \multirow[t]{5}{*}{ Squamous papilloma } & 1 & 1 & 1 & 2 \\
\hline & 2 & 3 & 2 & 5 \\
\hline & 3 & 1 & 2 & 3 \\
\hline & 4 & 2 & 2 & 4 \\
\hline & 5 & 3 & 3 & 6 \\
\hline \multirow[t]{6}{*}{ Squamous cell carcinoma } & 1 & 1 & 1 & 2 \\
\hline & 2 & 3 & 2 & 5 \\
\hline & 3 & 3 & 3 & 6 \\
\hline & 4 & 1 & 1 & 2 \\
\hline & 5 & 2 & 2 & 4 \\
\hline & 6 & 2 & 1 & 3 \\
\hline \multirow[t]{4}{*}{ Infundibular keratinizing acanthoma } & 1 & 1 & 1 & 2 \\
\hline & 2 & 2 & 2 & 4 \\
\hline & 3 & 1 & 1 & 2 \\
\hline & 4 & 4 & 3 & 7 \\
\hline \multirow[t]{5}{*}{ Inferior tricholemmoma } & 1 & 3 & 3 & 6 \\
\hline & 2 & 2 & 2 & 4 \\
\hline & 3 & 2 & 1 & 3 \\
\hline & 4 & 2 & 3 & 6 \\
\hline & 5 & 4 & 3 & 7 \\
\hline \multirow[t]{2}{*}{ Isthmic tricholemmoma } & 1 & 3 & 3 & 6 \\
\hline & 2 & 3 & 3 & 6 \\
\hline \multirow[t]{12}{*}{ Trichoblastoma } & 1 & 4 & 3 & 7 \\
\hline & 2 & 4 & 3 & 7 \\
\hline & 3 & 4 & 3 & 7 \\
\hline & 4 & 4 & 2 & 6 \\
\hline & 5 & 4 & 3 & 7 \\
\hline & 6 & 4 & 3 & 7 \\
\hline & 7 & 3 & 3 & 6 \\
\hline & 8 & 4 & 3 & 7 \\
\hline & 9 & 3 & 3 & 6 \\
\hline & 10 & 4 & 3 & 7 \\
\hline & 11 & 4 & 1 & 5 \\
\hline & 12 & 2 & 2 & 4 \\
\hline \multirow[t]{7}{*}{ Trichoepithelioma } & 1 & 2 & 2 & 4 \\
\hline & 2 & 4 & 3 & 7 \\
\hline & 3 & 3 & 2 & 5 \\
\hline & 4 & 3 & 3 & 6 \\
\hline & 5 & 2 & 3 & 5 \\
\hline & 6 & 1 & 2 & 3 \\
\hline & 7 & 3 & 2 & 5 \\
\hline \multirow[t]{3}{*}{ Malignant trichoepithelioma } & 1 & 3 & 2 & 5 \\
\hline & 2 & 3 & 2 & 5 \\
\hline & 3 & 2 & 3 & 5 \\
\hline \multirow[t]{2}{*}{ Pilomatricoma } & 1 & 3 & 2 & 5 \\
\hline & 2 & 2 & 3 & 5 \\
\hline Subungual keratoacanthoma & 1 & 0 & l & 0 \\
\hline \multirow[t]{4}{*}{ Subungual squamous cell carcinoma } & 1 & 2 & 2 & 4 \\
\hline & 2 & 1 & 2 & 3 \\
\hline & 3 & 1 & 1 & 2 \\
\hline & 4 & 1 & 2 & 3 \\
\hline
\end{tabular}

\section{Inferior tricholemmoma}

Sox9 showed a variable positivity in all 5 tricholemmoma cases. The number of positive cells usually ranged from $25 \%$ to $50 \%$ (3 cases), with intensity of staining from weak to intense. Two tumors were diffusely (50-100\% of positive cells) and strongly positive. 


\section{Isthmic tricholemmoma}

In both isthmic tricholemmomas, positive cells varied from $50 \%$ to $75 \%$ of neoplastic cells. An intense immunolabeling was detected and involved mainly peripheral basal cells.

\section{Trichoblastoma}

All 12 trichoblastoma (Figure 1C) were Sox9 positive; 9 tumors were diffusely positive (75$100 \%$ of neoplastic cells in 7 cases, $50-75 \%$ in 2 cases) with an intense staining, whereas in 1 case Sox 9 showed diffuse (75-100\% of cells) but weak, immunolabeling. In 2 cases there was a variable percentage of positive cells (from $25 \%$ to $100 \%$ ) with a moderate intensity of staining.

\section{Trichoepithelioma}

Four of 7 trichoepitheliomas (Figure 1D) showed a very wide percentage of positive cells, ranging from 1-25\% to 75\%; Sox9 immunolabeling was moderate. In 3 cases, $25-50 \%$ to $75-$ $100 \%$ of the tumor cells showed an intense staining. Sox 9 was detected mainly in peripheral basal cells and in suprabasal cells with spinous differentiation. Only in 1 case a rare and weak immunolabeling was observed.

\section{Malignant trichoepithelioma}

All 3 tumors expressed Sox 9 . The percentage of positive cells varied from $25-50 \%$ ( 1 case) to $75-100 \%$ ( 2 cases). The intensity was usually moderate (2 cases) or intense (1 case). Peripheral basal cells and suprabasal cells were mostly positive.

\section{Pilomatricoma}

The 2 tumors expressed from 25\% to $75 \%$ of positive cells, with a moderate to intense Sox 9 positivity (Figure 1E).

\section{Subungual keratoacanthoma}

Sox9 was negative in neoplastic keratoacanthoma cells. Internal control, represented by normal skin hair follicles, was mildly positive.

\section{Subungual squamous cell carcinoma}

The percentage of positive cells in subungual squamous cell carcinomas (Figure 1F) ranged from $1-25 \%$ (3 cases) to $25-50 \%$ (1 case) of positive cells. The intensity of immunolabeling varied from weak (1 case) to moderate (3 cases), especially in spinous and basal layer. Immunolabeling decreased or disappeared in most differentiated cells.

\section{Discussion}

Genes involved in developmental processes or tissue homeostasis maintenance are often overexpressed in tumorigenesis. ${ }^{3,11}$ Sox9 is implicated in a wide range of human neoplasms, especially in organs where it plays a role in their developmental stages and in stem cells maintenance, ${ }^{3,11}$ but it has been found even in other neoplasms, as fibrosarcomas, where $\operatorname{Sox} 9$ is not known to be required during normal physiology. ${ }^{11}$ As regards skin, Sox9 is present in the outer root sheet of human hair follicle and sebaceous gland, especially in basal layers; Sox 9 has been also detected in basal layer of interfollicular epidermis, too. ${ }^{1}$ In canine normal skin, Sox 9 positive cell distribution was similar to that reported in humans. ${ }^{3,8}$ In a few cases scattered $\operatorname{Sox} 9$ positive epithelial cells were detected also in upper hyperplastic epidermis above the neoplastic tissue; similar findings have been described in humans by Vidal et $a l .{ }^{3}$ and Shi et al. ${ }^{1}$ This gene, indeed, is required for the specification of early bulge cells and its progeny; moreover it is responsible of maintenance of stem cells characteristics in the adult bulge niche, whose action is
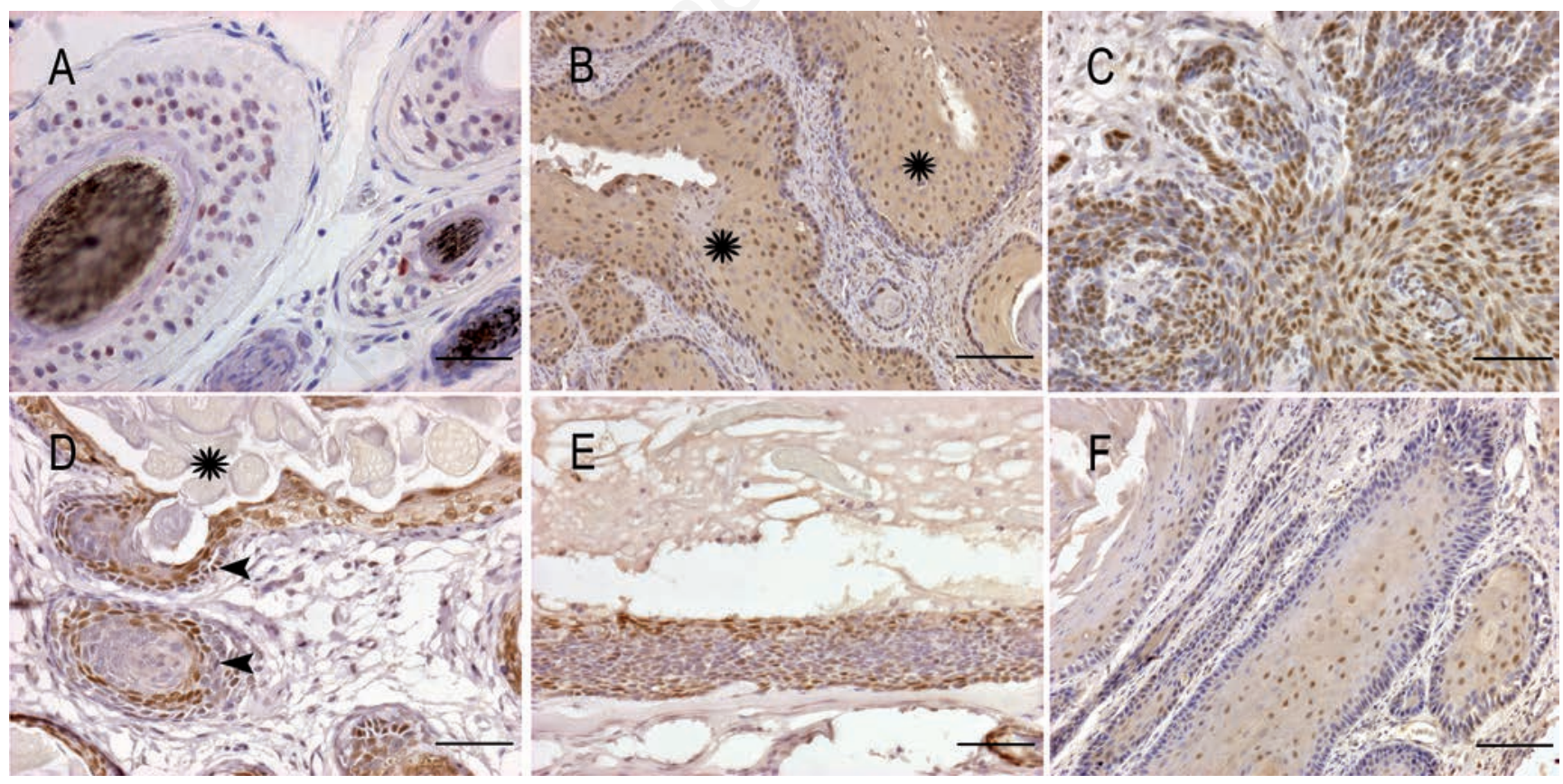

Figure 1. Sox9 immunohistochemistry. A) Hair follicle positive control: transverse sections with various positive nuclei. B) Squamous cell carcinoma: intense, diffuse, irregular nuclear positivity in neoplastic cells with basal and spinous differentiation (asterisks); positive cells are also detected in reactive fibrous stroma. C) Trichoblastoma: cords and spirals of neoplastic epithelial cells almost entirely positive for Sox9. D) Trichoepithelioma; abundant keratin (asterisk) surrounded by basal and suprabasal epithelial cells intensely positive (arrows). E) Pilomatricoma: wall of a neoplastic cyst with positive cells mostly in superficial layers. F) Subungual squamous cell carcinoma with scattered positive spinous cells. Scale bars: A,C,D) $75 \mu \mathrm{m}$; B,F,E) $150 \mu \mathrm{m}$. 
necessary in a wound environment. ${ }^{4}$

As previously described by some authors, ${ }^{4,8}$ various cutaneous neoplasms mirror some of Sox9 embryological expression patterns, sometimes even reflecting its spatial distribution within the various follicular subcompartments. ${ }^{8}$ Sox 9 was detected in all the adnexal tumors tested, with the exception of subungual keratoacanthoma, maybe due to its origin from the nailbed epithelium. ${ }^{12}$ Subungual squamous cell carcinomas resulted moderately positive. As for subungual keratoacanthoma, the origin from a highly differentiated epithelium could explain the reduced $\operatorname{Sox} 9$ expression as well as the loss of other stem cell markers. ${ }^{13}$ Sox 9 expression in epidermal keratinocytes indeed, is prominently detected in undifferentiated rather than in differentiated keratinocytes. ${ }^{1}$ Sox 9 was expressed at the highest levels in neoplasms strictly related to embryonal hair follicle, as trichoblastomas. Both in human and veterinary medicine, trichoblastomas are considered to be neoplasms deriving from hair follicle stem cells; ${ }^{14}$ our findings therefore support this hypothesis and confirm the results of other studies performed in dogs employing different stem cell markers. ${ }^{13,15,16}$ The intensity of immunolabeling and number of Sox 9 positive cells may be related to the cycling and bulgeharboring portion of the follicle, respectively represented by the hair stem and the isthmus. ${ }^{8}$ Sox9 immunolabeling was observed in high percentage of cells also in tricholemmomas and trichoepitheliomas especially in peripheral basal cells and in less differentiated suprabasal cells. Regarding trichoepithelioma, the heterogeneity in $\operatorname{Sox} 9$ staining may reflect the origin of this neoplasm from the three different parts of the hair follicle. ${ }^{12,13}$ Malignant trichoepitheliomas, in lesser extent, show the same immunolabeling variability.

Tricholemmomas, both inferior and isthmic type, showed a variable positivity especially in basal and suprabasal layers, but no relevant differences in immunohistochemical reactivity were observed. There is no general agreement about the origin of these neoplasms; they are supposed to derive respectively from the inferior segment of the outer root sheet or from the isthmus segment of the outer root sheet; experimental data are rather controversial. ${ }^{3,13}$ Squamous cell carcinomas, both epidermal and subungual type, and squamous papillomas expressed Sox 9 with various degrees of positivity. Squamous cell carcinoma was irregularly $\operatorname{Sox} 9$ positive in accordance with previous studies where different markers for stem cells were considered. ${ }^{1,17,18}$ Sox 9 expression patterns in pilomatricomas resemble those of the developing and the post-natal hair follicle. ${ }^{8}$ In the current study, according with a previous work by Krahl and Sellheyer, ${ }^{8}$ basaloid cells/bulb germ cells were $\operatorname{Sox} 9$ negative, while a $\operatorname{Sox} 9$ positivity was observed in more differentiated cells. These neoplasms, therefore, have to be considered as trichoepitheliomas with a prominent matrical component.

In recent years many efforts have been made to find a logical classification of adnexal tumors according to a new molecular-morphological characterization, investigating neoplasm stem cell biology. ${ }^{17}$ Regarding canine tumors, the association between hair follicle and various stem cell markers, as CD34, CK15 and Nestin, has been investigated, ${ }^{13,15,16}$ each with its own characteristics feature and target. Sox 9 may be proposed as another reliable stem cell marker for dermopathologists to better assess the role of stem cells in canine epidermal and follicular tumors.

\section{References}

1. Shi G, Sohn KC, Li Z et al. Expression and functional role of Sox9 in human epidermal keratinocytes. PLoS One 2013;8: e54355.

2. Akiyama H. Control of chondrogenesis by the transcription factor Sox9. Mod Rheumatol 2008;18:213-9.

3. Vidal VPI, Ortonne N, Schedl A. Sox9 expression is a general marker of basal cell carcinoma and adnexal-related neoplasms. J Cutan Pathol 2008;35:373-9.

4. Nowak JA, Polak L, Pasolli HA, Fuchs E. Hair follicle stem cells are specified and function in early skin morphogenesis. Cell Stem Cell 2008;3:33-43.

5. Mercati F, Pascucci L, Ceccarelli P, Dall'Aglio C, Pedini V, Gargiulo AM. Expression of mesenchymal stem cell marker CD90 on dermal sheath cells of the anagen hair follicle in canine species. Eur J Histochem 2009;53:159-66.

6. Vidal VP, Chaboissier MC, Lutzkendorf S, Cotsarelis G, Mill P, Hui CC, et al. Sox9 is essential for outer root sheath differentiation and the formation of the hair stem cell compartment. Curr Biol 2005;15:1340-51.

7. Christiano AM. Hair follicle epithelial stem cells get their Sox on. Cell Stem Cell 2008;3:3-4.

8. Krahl D, Sellheyer K. Basal cell carcinoma and pilomatrixoma mirror human follicu- lar embryogenesis as reflected by their differential expression patterns of Sox9 and beta-catenin. Br J Dermatol 2010;162: 1294-301.

9. Rao P, Fuller GN and Prieto VG. Expression of Sox9 in metastatic melanoma - A potential diagnostic pitfall. Am J dermatopathol 2010;32:262-6.

10. Kobayashi T, Iwasaki T, Amagai M, Ohyama M. Canine follicle stem cells candidates reside in the bulge and share characteristic features with human bulge cells. J Invest Dermatol 2010;130:1988-95.

11. Matheu A, Collado M, Wise C, Manterola L, Cekaite L, Tye AJ, et al. Oncogenicity of the developmental transcription factor Sox9. Cancer Res 2012;72:1301-15.

12. Goldschmidt MH, Dunstan RW, Stannard AA, Von Tscharner C, Walder EJ, Yager JA. Histological classification of epithelial and melanocytic tumor of the skin of domestic animals. In: World Health Organization Classification of Tumors of Domestic Animals. Second series, vol. 2, Washington DC, USA: Armed Forces Institute of Pathology, American Registry of Pathology; 1998.

13. Brachelente C, Porcellato I, Sforna M, Lepri E, Mechelli L, Bongiovanni L. The contribution of stem cells to epidermal and hair follicle tumors in the dog. Vet Dermatol 2013;24:188-e41.

14. Hurt MA, Kaddu S, Kutzner H, Cribier B, Schulz T, Hartschuh W. Benign tumors with follicular differentiation. In: World Health Organization Classification of Tumours, Pathology and Genetics of Skin Tumours. Lyon: IARC press; 2006.

15. Pascucci L, Mercati F, Gargiulo AM, Pedini V, Sorbolini S, Ceccarelli P. CD34 glycoprotein identifies putative stem cells located in the isthmic region of canine hair follicles. Vet Dermatol 2006;17:244-51.

16. Mercati F, Pascucci L, Gargiulo AM, Dall'Aglio C, Ceccarelli P. Immunohistochemical evaluation of intermediate filament nestin in dog hair follicles. Histol Histopathol 2008;23:1035-41.

17. Sellheyer K. Stem cell markers can help identify adnexal tumor differentiation when evaluated in the context of morphology: methodology matters. J Cutan Pathol 2011;38:460-74.

18. Bongiovanni L, Malatesta D, Brachelente C, D'Egidio S, Della Salda L. $\beta$-catenin in canine skin: immunohistochemical pattern of expression in normal skin and cutaneous epithelial tumours. J Comp Pathol 2011;145:138-47. 